Artigos

\title{
Cachorros e humanos Mercado de rações pet em perspectiva sociológica
}

\author{
Dogs and humans \\ Pet food market from the sociological perspective \\ Marcia da Silva Mazon*
Wandgleisom Garcia de Moura**
}

Resumo: O artigo discute mudanças no mercado de rações para animais de estimação a partir do referencial da Sociologia Econômica. Os dados empíricos utilizados são provenientes de entrevistas realizadas com veterinários e donos de pet shops, todas realizadas em Florianópolis, estado de Santa Catarina. Ao longo do artigo abordamos o processo de globalização e suas consequências no mercado de rações. O movimento de fusões e aquisições de empresas multinacionais do setor de rações pet na década de 1990 constrói e é construído pela modulação do significado dos cachorros dentro dos lares. Inicialmente eles são bens úteis para proteger as casas e nas últimas décadas tornam-se parte dos lares, inúteis e consomem parte do orçamento familiar.

Palavras-chave: Estado. Mercado. Cachorros. Animais de estimação. Rações.

Abstract: The article discusses changes in the pet food market from the framework of Economic Sociology. Empirical data used are from interviews with veterinarians and pet shop owners, all held in Florianópolis, Santa Catarina State. In the article we discuss the process of globalization and its consequences in the feed market. The movement of mergers and acquisitions of multinational companies in the pet feed industry in the 1990s builds and is constructed by the modulation of the meaning of the dogs within the households. Initially they were useful goods to protect homes while in recent decades they became part of the household, being useless and consuming part of the family budget.

Keywords: State. Market. Dogs. Pets. Feed.

\footnotetext{
* Doutora em Sociologia Política pela Universidade Federal de Santa Catarina (UFSC, Florianópolis, SC, Brasil) é professora adjunta do Departamento de Sociologia e Ciência Política na mesma universidade e editora da Revista Política e Sociedade e coordena o Núcleo de Sociologia Econômica (Nusec). A primeira versão deste artigo foi apresentada no $40^{\circ}$ Encontro Anual da Anpocs em Caxambú no Gt 31: Sociedade e Vida Econômica, em 2016. Agradeço as críticas e sugestões dos debatedores < marciadasilvamazon@yahoo.com.br>.

***Bacharel em Ciências Sociais pela Universidade Federal de Santa Catarina e membro do Núcleo de Sociologia Econômica (Nusec) na mesma universidade<nani_wandy@hotmail.com>.
} 


\section{Introdução}

Raro atualmente quem não tenha amigo ou vizinho com um cachorro considerado membro da família. É um fenômeno espantoso o crescimento do número e do grau de afeto dedicado aos animais de estimação nas últimas décadas. O IBGE revela que já é maior o número de lares com cachorros do que com crianças (Ritto; Alvarenga, 2015). Há uma estimativa da existência de um bilhão de cachorros no planeta nos dias atuais (Gromper, 2014). ${ }^{1}$ Técnicas para tratamento médico e aumento de longevidade principalmente de cães e gatos têm sido objeto de inúmeros investimentos. ${ }^{2}$

É importante não esquecer que os gatos também podem fazer parte da família, e este é o caso em muitos lares. No entanto, como o cão é a primeira espécie animal domesticada e é o animal mais presente nos lares, elegemos os cães como objeto de análise. Igualmente há cerca de 10 mil anos atrás, desenvolveu-se a prática de enterrar cães. Nenhuma outra espécie animal é incluída tão consistentemente em rituais mortuários humanos (Morell, 2015, p. 33).

A convivência de cachorros com humanos tem uma história que começa a ser novamente datada a partir de pesquisas recentes. ${ }^{3}$ Diz-se novamente porque achados anteriores supunham que a convivência com humanos fosse um evento associado à agricultura. Novas pesquisas mostram que os cães atuais não descendem do lobo cinzento (como se acreditava até muito recentemente), mas sim de um lobo desconhecido e extinto, e também que a domesticação ocorreu enquanto humanos eram caçadores e coletores (Freedman et al., 2014; Larson, 2012). A novidade é que não foram os humanos que domesticaram os cães-lobos, mas estes últimos que se aproximaram dos humanos por conta própria, identificando-os como um novo nicho ecológico que podiam explorar (Larson, 2012). ${ }^{4}$

\footnotetext{
${ }^{1}$ Os cães (de maneira distinta aos gatos, os quais caçam pequenas presas) vivem em total dependência dos humanos (à exceção dos dingoes na Austrália) de maneira direta ou indireta (vivendo nas ruas e se alimentando de dejetos deixados pelos humanos). Segundo Gromper (2014), autor que estuda a relação de cachorros com animais silvestres, há uma quantidade preocupante de cachorros convivendo com esses animais silvestres, disputando alimento com eles, matando-os, espalhando patógenos e promovendo distúrbios no ecossistema.

2 Já existe um grande conjunto de medidas que autorizam e naturalizam a utilização de tecnologias médicas, incluindo medicamentos para animais de estimação (Segata, 2015; Kulick, 2009). Conforme Ritto e Alvarenga (2015), técnicas aprimoradas de raio x foram desenvolvidas no sentido de fazer exames menos invasivos em animais de estimação e com maior detalhe.

${ }^{3}$ Novas técnicas de datação baseada em milhares de DNAs de lobos e cães modernos e primitivos e uma nova técnica de medir ossos conclui que os cães se originaram na Europa entre 32 mil e 19 mil anos atrás (Freedman et al., 2014).

${ }^{4} \mathrm{O}$ mais antigo inquestionável cão é um espécime de 14 mil anos encontrado em um sítio arqueológico na Alemanha mostrando não a domesticação utilitária, mas uma ligação afetuosa de um animal enterrado junto com uma família.
} 
Enquanto pesquisadores como Larson e Freedman desvendam as fronteiras genéticas entre lobos e cães, Tim Ingold (1995) convida a pensar fronteiras entre humanos e animais. Importante lembrar que o que encanta humanos é a docilidade e obediência dos cães. Diferentemente dos lobos, que mesmo em ambiente de domesticação não respeitam ordens, os cães estão sempre aguardando comandos humanos. Quatro alcateias de lobos e quatro matilhas de cães estão em estudo desde 2008 no Centro de Ciência do Lobo, na Áustria. Depois de sete anos, embora os dois grupos de animais tenham sido treinados a obedecer ordens básicas de comando, identificou-se que os lobos mantêm uma independência mental e um comportamento muito diferente do de cães. A compreensão canina do não absoluto pode estar associada, segundo pesquisadores deste centro, à estrutura de suas matilhas, que não são igualitárias como as alcateias dos lobos, mas ditatoriais (Morell, 2015, p. 28).

Ingold $(2010)^{5}$ observa que a captura, doma e procriação controladas constituem processos diversos e independentes que não necessariamente se apresentam associados e, por isso, a domesticação não pode ser definida por um ou outro aspecto. Segata (2012) observa que há negociações em torno da humanidade dos animais de estimação em particular: eles foram treinados para modular suas pulsões animais até chegarem ao ponto de gentis companheiros sentados nos sofás de casa em frente à televisão: sem rosnar, sem latir, cheirosos e dóceis. Importante aqui considerar que este não é único caminho da domesticação dos cães. Como mostra o estudo de Digard (2004) na França, a construção social do pitbull (que anteriormente servia de mascote aos regimentos de marinheiros) refere-se a um animal domesticado, porém, criado para o combate. ${ }^{6}$

De um lado, as explicações para a presença de cachorros nos lares surgem numa perspectiva da economia neoclássica como escolha dos seres humanos como atores racionais maximizadores de oportunidades que optam por cães (às vezes gatos, coelhos, papagaios etc.) como forma de preencher o vazio de lares modernos, ninhos vazios de crianças na sociedade industrial. De outro, autores como Ingold (2010) e Digard $(2003,2004)$ fazem uma leitura dinâmica da relação entre humanos e animais mostrando como transformações

\footnotetext{
${ }_{5}$ Tim Ingold faz uma etnografia com renas e seus criadores, observando a relação entre humano, animal e território. Ele observa que houve uma mudança na prática de pastoreio para uma prática predatória quando os pastores começaram a mobilizar o snowmobile (trenó motorizado), o qual assusta as renas, já que elas os confundem com os predadores.

${ }^{6}$ Digard (2004) mostra que o fenômeno pitbull (que passa a ser midiatizado e politizado com adoção de leis contra animais perigosos em 1999) é tipicamente urbano e ele cresce em número nas periferias de Paris que utilizam o cão de maneira delituosa; fenômeno que cresce acompanhando as medidas repressivas.
} 
econômicas e sociais podem ser pensadas em associação com aspectos que permeiam a zoologia de uma espécie. Ingold critica a ideia de que quanto mais instaurada a dinâmica capitalista mais intensa a domesticação. Ele propõe pensar as relações produtivas entre humanos e animais. Na mesma direção Digard (2004, 2003) propõe pensar a construção social do animal doméstico como a resultante da soma de muitas lógicas em função das circunstancias e do jogo conjuntural. Desse modo, o que se propõe neste artigo é uma abordagem sociológica da relação entre humanos e animais na perspectiva dos mercados. Conforme Bourdieu (2000; 2005), Zelizer (1999) e Fligstein (2001, 2001a), mercados são arbitrários culturais que, para existirem, precisam do investimento de sentido, do preenchimento de significados. Exemplos da alta costura e dos mercados de casas próprias em Bourdieu (1976; 2000); em Zelizer (1992 [1978]; 1994 [1985]) dos seguros de vida, do mercado de adoção de bebês; e em Fligstein (2001), a emergência do mercado de informática nos EUA.

Zelizer tece uma crítica ao que ela nomeia como mercado 'ilimitado' presente tanto na visão marxista como em Polanyi: a ideia de que o contato com a troca mercantil corromperia laços pessoais e valores tão bem como a presença de sentimentos na esfera do mercado seria fonte de ineficiência; este raciocínio promove uma crítica ideológica no plano do absolutismo econômico. Na outra ponta igualmente Zelizer alerta para a visão de complacência ideológica presente nas análises que anunciam um determinismo cultural, como em Douglas e Isherwood (2006 [1979]). Estes autores, segundo Zelizer, olham para o mercado como pura construção de significados. A primeira abordagem promove censura ideológica e minimiza a capacidade de construção de significado dos atores, a segunda visão, segundo Zelizer, subjetiviza em excesso a realidade e exclui a realidade material, minimiza a capacidade de força de grupos dominantes. Zelizer propõe um caminho entre as duas visões que ela nomeia como mercados múltiplos ou vidas conexas. Fazendo uma retomada de Weber, ela propõe pensar as relações de interinfluência entre as diferentes esferas ou efeitos recíprocos, sem nenhum a priori (Zelizer (2011; 2011a).

Esta autora examina a alternância de significados proporcionada pelo mercado de crianças para adoção (Zelizer, 1994 [1985]). Num primeiro momento, da passagem do século 19 para o 20, as crianças adotadas situavamse na faixa etária entre 6 a 12 anos de idade, sexo masculino, e o objetivo da adoção era o de que elas fossem úteis nas tarefas do dia a dia. Na passagem do século e alimentada pela influência da adoção dos atores famosos, a adoção passa a ser de meninas, bebês e de olhos claros, para se tornarem herdeiras. Ao 
invés de contribuírem no orçamento, elas participam dos gastos do orçamento familiar. Transferindo este raciocínio para a relação de humanos com animais de estimação, interrogamos: quais negociações de sentido transferem os cachorros de moradores do quintal, úteis na vigia da casa, para habitantes que compartilham sofá e intimidade que, além de inúteis, consomem parte significativa dos orçamentos familiares? Como considera Segata (2012), o núcleo de construção da ideia de que os animais de estimação devem fazer parte dos lares ativa uma chave de equivalência moral na qual os cachorros também são gente. Este é um apelo constante e igualmente se nutre da equivalência biológica de que humanos também são animais; lógicas em balanço no processo de construção desta convivência entre humanos e cães. Como chegamos a este balanço? Os motivos são inúmeros. Neste artigo focaremos a emergência do mercado de rações para animais de estimação (nomeado como pet food) como elemento que constrói a relação de humanos com animais ao mesmo tempo em que é construído num processo de interatuação.

O objetivo deste artigo é analisar o crescimento do mercado de rações para animais de estimação (pets), em particular dos cachorros, e refletir sobre a construção de significados que torna a presença desses seres nos lares algo razoável.

$\mathrm{O}$ artigo está dividido em duas seções. Na primeira, observamos alguns aspectos da conformação do mercado de rações pet no Brasil a partir de dados de sítios da internet e do Ministério da Indústria e do Comércio. Igualmente, foram elaboradas entrevistas com profissionais envolvidos no mercado de pets: veterinários, vendedores e gerentes de distribuição de ração. Foi realizada ainda uma entrevista em profundidade com um proprietário daquilo que foram as casas de agricultura e que posteriormente se especializaram como pet shops. Na segunda seção, analisamos o mercado de rações a partir da adaptação informada pelo mercado de rações que modifica a posição do animal de estimação dentro dos lares numa relação de interinfluência.

\section{O mercado de rações pet em perspectiva sociológica}

Fligstein (2001a) questiona a ideia de racionalidade da economia neoclássica afirmando que os atores do mercado habitam mundos obscuros e nunca se sabe qual ação terá qual resultado, já que é impossível prever a ação dos demais atores do mercado. Neste sentido, é mais fácil compreender a ação no mercado pela maneira como as empresas olham para seus vizinhos de mercado mais do que pela forma como observam seus clientes: eles se acomodam nos respectivos nichos de mercado, evitando uma guerra aberta. Conforme Bourdieu (2005) e Fligstein (2001a) o mercado constitui-se a 
partir de lutas, nas quais os atores disputam espaços num processo políticocultural. Bourdieu (1982; 2008) acrescenta também a ideia do efeito da teoria ou performatividade: a ciência econômica e sua capacidade de fazer existir aquilo que descreve. Nesse sentido, interessa-nos mapear alguns dos atores que constroem o mercado de rações pet e diferentes discursos que o legitimam. Importante lembrar que, há algumas décadas, os animais de estimação eram alimentados com restos de comida da própria casa e progressivamente a alimentação se torna item de mercado. Há uma especialização em diferentes estilos de rações, hoje capitaneado por empresas pet food multinacionais.

No Brasil, nas décadas de 1980 e de 1990, houve uma reversão de tendências no setor de rações, acompanhando mudanças ocorridas nos mercados europeu e norte-americano. O crescimento da importância e do afeto destinado aos animais de estimação, ao mesmo tempo que constitui, é constituído pelo surgimento do mercado de rações. Segundo Bourdieu (2008), os estilos de vida e as preferências por determinados produtos são parte de uma construção cultural que se realiza segundo regras muito particulares. Bens e objetos só despertam interesse e adquirem sentido para aqueles que possuem os códigos específicos segundo os quais esses objetos são codificados. Esta reflexão nos permite vislumbrar de que maneira as rações pet se transformam em bens de mercado e se diferenciam em produtos variados (Abinpet, 2016; Marichalar, 2006).

\section{Aspectos históricos do mercado de rações pet - um arbitrário cultural}

Apresentamos aspectos históricos sem a pretensão de esgotar o tema. O intuito é apresentar aspectos iniciais, os quais deram impulso a uma lógica de mercado.

Conforme Kulick (2009), a indústria pet food é uma criação relativamente recente. Segundo Gates (2008), esta indústria surgiu em 1860 na Inglaterra, com a invenção do primeiro biscoito canino por James Spratt. Spratt inspirouse quando viu cachorros comendo biscoitos em meio ao lixo nas docas de Londres. O biscoito era feito de vegetais, sangue bovino, farinha de trigo e beterraba. O alimento torna-se popular e chega aos EUA em 1890. Um desafio enfrentado pela indústria de alimentos para animais de estimação foi criar uma demanda para um produto que nenhum dono de animal supunha como uma necessidade.

Ao estilo dos gigantes da indústria do final do século 19, Spratt mobilizou uma publicidade implacável por meio de afirmações espalhafatosas de que a 
comida industrializada para animais de estimação era melhor do que sobras da mesa. ${ }^{7}$

Em que pese o paradoxo da situação já discutido na literatura (um animal alimenta outro intermediado por humanos), segundo Gates (2008), durante a Primeira Guerra Mundial começou a ser produzida a carne de cavalo enlatada para cães a partir de animais abatidos em combate. $\mathrm{O}$ fenômeno é nomeado por Digard (2012) como virada obscurantista ou paradoxo ocidental: de um lado livramo-nos de alguns animais de maneira violenta com exploração impiedosa e cada vez mais massiva e banalizada e de outro superprotegemos animais de companhia; são tratados como ou melhor do que crianças. O enlatamento citado por Gates permitia alta durabilidade, produção em escala e exportação. Entretanto, na Segunda Guerra Mundial, o alumínio utilizado nas latas foi racionado para o esforço de guerra, promovendo a substituição do alimento enlatado por rações secas. Em decorrência desse fato, em 1946 o alimento seco representava $85 \%$ do mercado. A próxima inovação veio em 1950, com o processo denominado como extrusão. Nele, os ingredientes são cozidos juntos na forma líquida e pressionados por meio de um extrusor mecânico. O extrusor expande o alimento a altas temperaturas, assando a mistura e provocando sua solidificação. Essa tecnologia permite alta durabilidade e é utilizada até hoje na produção de ração seca (Gates, 2008).

A criação de animais no pós-guerra - antes familiar e de pequeno porte - passa a se concentrar a partir dos anos de 1950. A produção passa por um processo de industrialização, intensificação, especialização na cadeia (Perrota, 2016). Há uma multiplicação da população com menos tempo para refeições, o consumo de carne congelada e vendida em frações se expande rapidamente. As relações entre humanos e animais tornam-se mais impessoais para os animais que servem como alimento e mais personalizadas para os animais de companhia (Digard, 2012).

\section{Década de 1990: a emergência de um mercado mundial}

Para discutir as mudanças de mercado é fundamental situar a década de 1990 e a entrada do Brasil na Organização Mundial do Comércio (OMC). No Brasil, a partir da década de 1980, as instituições privadas são vistas como a

\footnotetext{
${ }_{7}$ O período do final do 19 e início do 20 é dominado pelo que Fligstein (1990) chama de concorrência direta, em que as empresas brigavam entre si e tentavam dominar o mercado sem grande interferência do estado e usando de todos os tipos de estratégias para convencer a população da importância dos seus produtos e para derrubar os concorrentes a qualquer preço, conforme as biografias de Carnegie, Ford, Morgan e Rockefeller confirmam. Isto termina com o Scherman Act.
} 
solução para os problemas do aparato público. Dentro da agenda de reformas estabelecida para tal período, a privatização das empresas públicas foi o item que mais avançou no País (Tavares de Almeida, 1999). Em alguns setores da economia, incluindo aí alimentos e ração para animais, há o fortalecimento de instituições privadas.

O processo chamado de globalização aumentou o número de conexões entre os diversos países em termos do intercâmbio de bens, tecnologia, serviços e difusão dos veículos de mídia de massa. Isso aconteceu junto com o processo de concentração da indústria alimentar e do varejo. As transformações foram iniciadas na segunda metade do século 20 e aceleradas no coro entoado pelos países de alta renda para uma abertura dos mercados nesses termos. Nesse período, agências multilaterais, como o FMI e o Banco Mundial, acompanhadas da maioria dos países de alta renda, promoveram a agenda do livre-comércio como panaceia para os males dos países de baixa renda (Mazon, 2009).

A partir de meados dos anos 1980, a indústria de pet food no Brasil apresentou um grande crescimento. Dados de estudos realizados por órgãos de pesquisas como o Instituto Brasileiro de Opinião Pública e Estatística (Ibope), o Instituto Brasileiro de Geografia e Estatística (IBGE) e a Anfalpet indicam que os anos posteriores a 2005 dão a dimensão do crescimento desse mercado. O Brasil, conforme dados da Anfalpet (2015), é o segundo país do mundo com maior população de animais domésticos, ficando apenas atrás dos EUA. São 52,2 milhões de cães e 22,1 milhões de gatos.

Segundo estimativas do Ibope, cerca de $59 \%$ dos domicílios brasileiros têm algum animal de estimação, e em $44 \%$ deles há pelo menos um cão, e em $16 \%$, um gato. Os números revelam que o gasto médio com produtos e serviços per capita/ano é de R $\$ 390$ entre pet food, produtos farmacêuticos, vacinas, embelezamento e acessórios - um total de $\mathrm{R} \$ 16$ bilhões de faturamento do setor no mercado. A pesquisa revela também que $63 \%$ das famílias brasileiras de classe A e B possuem pets e os consideram como integrantes da família. Este número passa para $64 \%$ na classe $\mathrm{C}$ e $55 \%$ na D. Outro estudo realizado pelo Sebrae-SP aponta que há cerca de oito mil pet shops em todo o País, responsáveis por gerar mais de 30 mil empregos.

Segundo estimativas da Anfalpet (2015), o mercado pet no Brasil, em 2011, faturou $13 \%$ mais que no ano de 2010. Desse faturamento total, o segmento de rações representa aproximadamente $66 \%$, o que corresponde a R\$8.209 bilhões. Em volume de produção, o segmento de pet food fechou o ano de 2011 com 1,98 milhão de toneladas e com crescimento de $6 \%$ em relação a 2010. O segmento pet food movimenta quase US\$70 bilhões no mundo, dos quais $6 \%$ cabem ao Brasil (As Perspectivas..., 2011). 
A Associação Brasileira da Indústria de Produtos para Animais de Estimação (Abinpet) também reforça o espantoso crescimento do mercado pet, afirmando que o mercado faturou $\mathrm{R} \$ 16$ bilhões em 2014, colocando o Brasil na terceira posição no ranking mundial. Segundo Márcio Bertolini, coordenador estadual do segmento pet do Sebrae-SP (citado em: Zuini, 2015), "Não há crise no mercado pet". Ele complementa informando que o principal impulsionador deste mercado hoje é o segmento de alimentação, que representa $67 \%$ do faturamento: "Na crise, pode ser que o consumidor troque de marca, mas ele não deixa de comprar".

Estima-se que hoje o parque industrial brasileiro conta com 130 fábricas de alimento para animais de estimação e aproximadamente 600 marcas desse produto. Essa produção é feita por empresas nacionais e multinacionais, as quais são líderes mundiais neste setor. Entre os principais fabricantes, há as multinacionais Nestlé Purina, Hill's Pet Nutrition (do grupo ColgatePalmolive), Masterfoods South America - que representam as populares marcas Eukanuba, Royal Canin, Wiskas e Pedigree -, Guabi Pet Care, Total Alimentos, e as nacionais Alisul, Hercosul e Adimax. A Masterfoods, maior fabricante do setor, apresenta uma produção que corresponde a cerca de $60 \%$ do mercado de rações para felinos e $45 \%$ de rações para cães. Segundo estudos de Marichalar (2006), as 10 maiores empresas, grande parte multinacionais, detêm $80 \%$ do mercado pet food.

\section{Empresas, fusões e aquisições do setor}

Conforme mencionado no início desta seção, a partir da década de 1990 e acompanhando o processo de globalização, vários setores passam por processos de fusões e aquisições; este é o caso do mercado de rações.

A empresa norte-americana Mars Pet Care foi fundada em 1935 por um filho de Frank Clarence Mars, fundador de uma empresa de doces e chocolates na Inglaterra. Mobilizando o capital resultante do negócio de chocolates, Forrest Mars apostou no mercado de rações para animais de estimação com a aquisição da pequena empresa Chappel Brothers, proprietária das marcas Chappie (que mais tarde, em 1964, se transformaria na marca Pedigree) e Kitekat (Mundo das Marcas, 2006).

A maioria das pessoas naquela época considerava estranho alimentar um animal de estimação com um tipo de alimentação específica. No entanto, os proprietários de cães foram rapidamente conquistados pela Mars e sua marca Chappie, que não demorou muito para começar a produzir alimentos em larga escala. Acompanhando o movimento de globalização, o início do século 21 foi marcado por aquisições para o crescimento da Mars no mercado 
pet food, arrematando a marca francesa Royal Canin, em 2001. Em 2014, as marcas IAMS, Eukanuba e Natura, da Procter \& Gamble foram compradas pela Mars, nos Estados Unidos e na América Latina, por US\$2,9 bilhões. As regiões inclusas no acordo respondem por cerca de $80 \%$ das vendas globais da unidade (idem).

A empresa Purina foi fundada em janeiro de 1894 na cidade de St. Louis, no estado norte-americano de Missouri, por William H. Danforth e mais dois sócios, George Robinson e Will Andrews, com o nome de Robinson-Danforth Commission Company. Iniciou comercializando o alimento concentrado Omolene, primeira ração comercial para cavalos e mulas - na época eram animais vastamente utilizados como meio de transporte. Maud Purina, a mula de dentes arreganhados e com uma panela de maneira imprópria dependurada em seu rabo, tornou-se uma marca registrada popular da marca Omolene (Mundo das Marcas, 2006).

Os primeiros produtos eram misturados com uma pá e embalados em sacas de 175 libras (80 quilos) costuradas manualmente na fábrica localizada na cidade de St. Louis. O negócio de ração continuou crescendo, impulsionado pela popular frase "Onde pureza é soberana (Where purity is paramount)", expressão que dá origem a palavra Purina. Em 1902, após união com Webster Edgerly, um produtor de cereais, a empresa passa a ser nomeada como Ralston Purina Company. Em 1926, ingressa no mercado de rações para cães, no qual reinou absoluta nas décadas seguintes. Nesse momento, foi inaugurado o Purina PetCare Center, um centro de pesquisa e desenvolvimento de nutrição e bem-estar animal localizado nas redondezas da cidade de St. Louis. Em dezembro de 2001, acompanhando igualmente o processo de fusões e aquisições que ocorreram no mercado mundial, a empresa foi comprada pela Nestlé por US\$10,3 bilhões, formando a Nestlé Purina PetCare Company, maior empresa deste segmento no mundo (idem).

A Purina chega oficialmente ao Brasil em 1967, atuando no ramo das rações agropecuárias. Em 1973, lança a Kanina, seu primeiro alimento para cães. Inicialmente, o produto era direcionado a fazendeiros e criadores. Somente em 1977 decidiu ampliar a distribuição do produto, procurando contato mais direto com o consumidor. Bonzo, sua ração mais conhecida, chegou às lojas em 1978 (Mundo das Marcas, 2006a).

A Eukanuba, marca que hoje pertence à Mars, comercializa sua linha de produtos, como rações para cães e gatos, em mais de 80 países ao redor do mundo. Foi criada por Paul Iams, um nutricionista animal, fundador e proprietário da The Iams Company, empresa produtora de ração para animais de estimação fundada em 1946 com o objetivo de introduzir no mercado norte- 
americano uma marca de ração para cães voltada ao segmento super premium. Um segmento importante da indústria de alimentos para animais de estimação é o chamado premium, ou especial. São rações de etapas da vida, que possuem fórmula especial para animais novos ou seniores, e igualmente as comidas dietéticas. As rações para etapas da vida ou dietéticas chegam a custar o dobro das normais, a ração premium para animais de estimação é o mercado que mais rapidamente cresce nessa indústria (Kulick, 2009). De 1999 a 2002, as vendas das comidas especiais para animais de estimação aumentaram 10,2\% no total, e as de comida dietética cresceram 25\% (Koerner, 2003). Em 2005, elas compreendiam 38\% das vendas de comida para animais de estimação (Barnes 2005 apud Kullick, 2009).

Em 1969, quando foi lançada a primeira ração Eukanuba para cães, adicionou-se frango ao alimento seco para cães. Esse processo possibilitou níveis de proteínas de $25 \%$ e de lipídeos de $16 \%$, níveis diferenciados de outros alimentos existentes no mercado norte-americano. Em 2014, a Mars adquiriu a The Iams Company, proprietária da marca Eukanuba, o que levou a uma alta concentração do mercado de rações: duas gigantes do setor respondem por uma grande parte do mercado (Mars, 2014).

\section{Cachorros e humanos}

Thomas (2010 [1983], p. 152) menciona a moda que se inicia ao final da Idade Média, os cães de estimação. O spaniel no século 16, buldogue no 17; o requisito essencial era que o cão fosse muito pequeno para acompanhar a sua dona em diferentes ocasiões sociais. O século 19 será o período de ascensão das exposições caninas (1859) com a fundação do Kennel Club (1873) tão bem como a redação de vários poemas sobre cães (idem, p. 153). Franklin (1999) argumenta que a emergência das elites sociais urbanas britânicas no fim do século 19 foi acompanhada pela reestratificação da classificação canina. No início do século 20, os cães eram marcadores de um complexo sistema de identidade social. O Kennel Club e o sistema de pedigree são novidades; é pequeno o número de raças genéricas conhecidas. Posteriormente, houve um aumento na quantidade de raças e um aprimoramento dos critérios de julgamento morfológico, além do crescimento no número de criadores de cães com pedigree junto a um entusiasmo por algumas raças.

Em meados do século 20, as qualidades decorativas e de entretenimento de algumas raças de cães, especialmente na década de 1950, cresceram significativamente, tornando-se sinônimo de um estilo de vida luxuoso e requintado. Poodles, pequineses e outras raças eram muito populares (Franklin, 1999). 
Os animais tornaram-se, então, menos decorativos e objetos de diversão e passam a ser valorizados como companhia. Existe uma diversidade de produtos e serviços oferecidos, como os profissionais que os levam para passear, os adestradores cada vez mais capacitados e as lojas especializadas em acessórios e no fornecimento de preparados nutricionais e alimentos específicos para cada raça ou porte de pet. Conforme Thomas (2010 [1983]) as variações de comportamento dos seres humanos em relação aos animais assim como o significado dos animais para os humanos passam por ondas que vão do utilitarismo à ideia da natureza como fim em si mesma em diferentes momentos. ${ }^{8}$ No início da era moderna, o valor atribuído aos animais era negativo, ajudando a atribuir, por contraste, o que distinguia a espécie humana (idem, p. 53-54). A civilidade do ser humano estava marcada pela sua distinção em relação aos animais: "não estale os lábios como um cavalo" menção do manual de boas maneiras de Erasmo. Em outros momentos, como nos escritos de 1830 na Inglaterra, todas as espécies inferiores teriam sido feitas para servir propósitos humanos, há uma expectativa do comportamento dos animais em relação aos seres humanos: o cão deveria demonstrar lealdade afetuosa (Thomas, 2010 [1983], p. 25).

\section{A indústria de alimentação pet e o mercado brasileiro}

No Brasil, a mudança de hábitos de alimentação de animais de estimação igualmente passa por transformações, porém em momentos distintos. Na década de 1980, a maioria dos pets ainda era alimentada com os restos de comida de seus proprietários, e poucas indústrias de rações existiam e investiam no Brasil. Nesse ponto, dois fatores contribuíram para a expansão do segmento: o poder aquisitivo das populações dos grandes centros aumentou e os padrões de consumo se sofisticaram. Por outro lado, a evolução dos hábitos em favor dos alimentos industriais está associada a um conjunto de fatores cada vez mais difundidos: alimentação sadia, equilibrada e com grande variedade de produtos disponíveis no mercado e, principalmente, a praticidade (A força..., 2003).

O Ministério da Agricultura, Pecuária e do Abastecimento é o responsável pela regulamentação das rações para cães e gatos no Brasil, conforme Decreto n⿳ 6296, de 11 de dezembro de 2007 (Brasil, 2007). A Instrução Normativa $\mathrm{n}$ 9 , de 9 de julho de 2003, que regulamenta os padrões de identidade e

\footnotetext{
${ }^{8}$ Os animais domésticos eram considerados moralmente responsáveis. Treinavam-se cães e cavalos sob um complexo sistema de punição e recompensa e sob estrita disciplina. O antigo testamento prescrevia morte para animais envolvidos em homicídio não como punição mas como meio simbólico de expressar repulsa pelo crime (Thomas, 2010 [1983], p. 137).
} 
qualidade de alimentos completos destinados a cães, fixa limites em relação aos parâmetros de qualidade que devem ser obrigatoriamente seguidos pelas indústrias desse segmento (Brasil, 2003). Já a Instrução Normativa $\mathrm{n}$ - 30, de 5 de agosto de 2009, estabelece critérios e procedimentos para rotulagem de produtos destinados à alimentação de animais de companhia (Brasil, 2009).

Na próxima seção, apresentamos o relato de uma entrevista que mostra a passagem das casas agropecuárias para as lojas pet e a era da especialização no mercado de rações que acompanha a emergência de uma classe média no Brasil.

\section{O mercado de rações e a trajetória da família Sens}

Os negócios da família Sens ${ }^{9}$ se iniciam entre as décadas de 1950 e 1960. Radicados na comunidade de Taquaras, no interior de Rancho Queimado, SC, essa família já desempenhava atividades com a agricultura, a pecuária e um pequeno comércio. O patrono, senhor Francisco Sens, era o responsável pela fazenda da família, de onde obtinha renda a partir da criação de gado e outros animais. Juntamente com sua esposa, Olinda Sens, assumia o comércio de um armazém de secos e molhados localizado na vila de Taquaras.

Como não existiam escolas com ensino mais avançado para os filhos em Rancho Queimado, três dos filhos homens mudaram-se para a cidade de São José, SC. Nessa mudança, a família adquiriu uma propriedade nas imediações onde hoje é a divisa entre os municípios de São José, SC, e Florianópolis, SC. Nesse mesmo local, os filhos da família resolveram começar um negócio e montaram uma lanchonete. Passado algum tempo, dona Olinda e os filhos resolveram, então, abrir uma casa agropecuária, já que em toda a região da Grande Florianópolis existia apenas um empreendimento com este perfil. A Casa Agropecuária Sens foi o primeiro estabelecimento particular deste gênero na Grande Florianópolis.

A ascensão do negócio foi rápida. Os produtos comercializados no estabelecimento eram os mais variados: desde produtos para grande porte ou pequeno porte de animais (ração, medicamentos, ferraduras e até mesmo pintinhos que eram vendidos para criação), passando por utilidades para a lavoura (sementes, defensivos, adubos) e também utensílios domésticos como fogões, panelas de ferro e vassouras.

\footnotetext{
${ }^{9}$ Os dados apresentados nesta seção fazem parte da pesquisa de Trabalho de Conclusão de Curso do segundo autor intitulado "A construção social do mercado pet food no Brasil: estudo de caso da família Sens" defendida em 15 de julho de 2013 no curso de graduação em Ciências Sociais na Universidade Federal de Santa Catarina (Moura, 2013).
} 
No início da década de 1980 e com o volume dos negócios em torno da Casa Agropecuária ganhando maior proporção, a família resolveu expandir os negócios. Foram inauguradas outras quatro casas agropecuárias e um atacado agropecuário para a distribuição de ração, sementes, implementos e adubos. As novas casas estavam localizadas, respectivamente, ao lado da BR 101, na altura do Bairro Kobrasol, onde também se encontrava anexado o atacado agropecuário; no centro de Florianópolis, na Rua Felipe Schmidt - essas duas casas somadas à matriz do bairro Campinas tinham um caráter um pouco mais urbano; e os outros dois estabelecimentos ficavam no centro de Santo Amaro da Imperatriz, SC, e em São Pedro de Alcântara, SC, e possuíam um perfil mais voltado à agricultura e à pecuária.

Segundo relato de Isaías Sens, o volume de dinheiro movimentado pelas agropecuárias e pela distribuição de ração era tanto que foi preciso contratar uma pessoa exclusiva para cuidar das movimentações diárias que entravam em caixa.

\section{Do atacado ao varejo especializado: a construção de uma mentalidade}

As rações de cachorro, segundo relatos de entrevista do senhor Isaias Sens, tiveram início entre as décadas de 1970 e 1980:

Tratar cachorro para nós lá no sítio, do interior, era apenas sacudir a toalha da mesa; e os cachorros que se virassem com o resto que sobrava do almoço ou da janta. Nunca fizemos comida para cachorro ou gato lá no sítio, era como o pai e a mãe sempre diziam: 'lugar de bicho é na rua e deixem que se virem'. Mas o tempo foi passando, então apareceu o arroz para alimentar cachorro, pacotes com cinco quilos - era aquela parte do arroz que não servia para alimentação humana-, então as pessoas compravam para misturar com restos de ossos e pelancas de carne do açougue e alimentavam os bichos (Entrevista, Isaias Sens, 2012).

O informante relata que os negócios em torno do arroz para alimentação canina de início era pouco relevante. Porém, a partir da metade da década de 1970 , a procura por este produto começou a aumentar gradativamente, até tomar uma proporção bem rentável para a Agropecuária.

Lembro quando a mãe começou a comprar o arroz em maior quantidade, até o dia em que ela chegou a negociar meia carga de arroz para cachorro. Então fizemos uma grande pilha de arroz próximo à entrada do estabelecimento, e quando as pessoas vinham 
comprar esse tipo de mercadoria elas mesmas pegavam a quantidade de pacotes que elas desejavam, passavam no caixa, pagavam e iam embora. Até então não havíamos pensado em ganhar dinheiro com comida de cachorro (Entrevista, Isaias Sens, 2012).

Conforme relato do entrevistado, o mercado pet tem uma ascendência a partir da década de 1970, porém esse crescimento é lento e restrito à comercialização de um tipo específico de alimento: o arroz para alimentação canina. Eventualmente alguma medicação para o tratamento de enfermidade (neste caso, os remédios eram os mesmos usados em grandes animais).

A comercialização de pet food, alimentação industrializada com características nutricionais específicas para a raça canina, começou a surgir no Brasil entre a metade da década de 1970 e o início da década de 1980:

As primeiras rações que apareceram em nossas agropecuárias foram a Canina peletizada ${ }^{10}$, tinham o mesmo formato de apresentação das rações para crescimento e engorda de suínos, aves, bovinos e equinos, e as embalagens seguiam o mesmo padrão de apresentação, porém o peso era menor, com sacos de oito e quinze quilos. Nas embalagens vinham estampadas o nome da ração e a marca da indústria, assim como vinham impressos slogans que prometiam uma melhor nutrição e uma maior beleza a pelagem dos cães (Entrevista, Isaias Sens, 2012).

O entrevistado fala da insegurança dos primeiros anos de comercialização de rações. Era uma novidade:

No começo gerou certa estranheza e desconfiança comercializar um produto industrializado para cães, pois estávamos acostumados a comercializar apenas arroz e, além do mais, nenhum cliente havia procurado esse gênero de alimentação na Agropecuária (Entrevista, Isaias Sens, 2012).

A importância do papel dos prescritores de mercado no sentido dado por Bourdieu (2000) é observada nas declarações do entrevistado com destaque para a atuação do representante comercial, atuando como consultor:

Nas conversas com os representantes, essa era a grande tendência do mercado, comercializar ração para cães, já que essa forma de alimentação industrializada era bem mais prática para servir aos animais, sem dispêndio de tempo cozinhando arroz com carne. [...]

\footnotetext{
${ }^{10}$ Peletizada: comercializada em formato cilíndrico ou drágeas.
} 
os representantes nos indicaram incentivar as pessoas acostumadas a comprar o arroz canino para uma migração para a ração, $e$ que esse método se tornaria com o tempo uma maneira bem mais prática de se ganhar dinheiro. Minha mãe dizia que ração era para bicho que produzia trabalho e alimento, por exemplo, boi, porco, cavalo e galinha, e não para cachorro, que era um animal que não dava lucro. Porém os representantes defendiam a ideia que os cães eram os animais que faziam a guarda da casa e, portanto, deveriam sempre estar bem alimentados e vistosos para amedrontar os ladrões (Entrevista, Isaias Sens, 2012).

Ao longo da década de 1980, com o aumento significativo na venda de rações caninas, a família Sens resolveu aprimorar seus negócios em torno dos alimentos industrializados para cães. Nessa época, as principais indústrias de rações estavam instaladas nos estados de São Paulo e Rio Grande do Sul. Na década de 1990, ocorreu a divisão dos negócios da família Sens:

Cada vez mais percebiamos que as pessoas entravam na loja buscando alguma coisa relacionada a cachorro, gato ou passarinho. Como a venda de ração já era significativa, resolvemos ampliar a quantidade de marcas de ração, assim como os produtos novos que apareciam especificamente para esse mercado. Foi nessa época que ampliamos o setor de pet, comercializando produtos para higiene e limpeza, ossos defumados, casinhas, almofadas, acessórios e principalmente medicamentos para pequenos animais (Entrevista, Isaias Sens, 2012).

Nos anos 2000 acontece a transição mais evidente de agropecuária para pet; a tradicional Agropecuária Sens dá lugar ao Agropet Sens, loja especializada em pet shop. Com a mudança de direção que tomou o negócio, o nome da loja igualmente foi reformulado. O Sens passava a confiança da tradição da marca, porém agora muito mais relacionado ao moderno pet shop.

No ano de 2013, o Agropet Sens passou por um processo de modernização do estabelecimento, e a inspiração para a reforma veio de grandes lojas visitadas em São Paulo. A loja foi então dividida em setores: banho e tosa, estética canina, com tosas especiais e tratamentos veterinários; clínica veterinária com um veterinário contratado em tempo integral; o setor de rações separado por marcas e singularidades das raças, idades e doenças. A grande novidade que a loja lançou no mercado de Florianópolis foi uma exclusiva farmácia pet no estilo moderno de farmácias para humanos.

Os relatos trazidos pela entrevista mostram o processo de constituição do mercado de rações como movimento de interatuação: consumidores procuram 
pelos alimentos para seus animais ao mesmo tempo em que os comerciantes do setor são estimulados pelos revendedores das rações a oferecer o produto especializado. Este processo se faz inicialmente fazendo apelo ao aspecto utilitário dos animais (o cão vigia a casa) até o momento do processo de diferenciação em que os pet shops se transformam em casas especializadas, o setor se concentra em algumas multinacionais com crescimento anual significativo e os animais se tornam parte dos lares e do universo afetivo das famílias.

\section{Considerações finais}

Este artigo analisou aspectos da emergência do mercado de rações pet no Brasil a partir do referencial da Sociologia Econômica a qual questiona a ideia do ator racional e intercambiável da economia neoclássica, fazendo apelo à historicidade $\mathrm{e}$ ao contexto da troca.

Zelizer (1996) analisa a mudança de significado de diferentes objetos que transformam ou inauguram novas lógicas de circulação de bens pela sociedade. É possível afirmar que a lógica de circulação de cachorros de estimação anima e é influenciada pelo mercado de rações pet. Durante a década de 1990 e a partir das reformas liberalizantes, o Brasil viveu um movimento de fusões e aquisições de diversos setores da economia, incluindo o mercado de rações. Nesse setor, a partir do início do século 21, três multinacionais dominam o mercado: Purina, Mars PetCare e Procter \& Gamble.

Acompanhando esse processo, os animais de estimação passam por transformações de significado em sua relação com humanos. Nas últimas décadas, eles ganham o status de membros da família e o mercado de bens que os cercam não para de crescer: Pet shops especializados, brinquedos para animais, terapias, programas de televisão sobre como educar e cuidar de animais de estimação, programas para os próprios animais como Petflix e o mercado de rações, foco deste artigo. Os bichos que outrora ficavam no entorno das casas e eram alimentados com as sobras do que os humanos comiam - sendo parte da vigilância da casa - agora são considerados predominantemente parte dos lares e consomem uma fatia significativa da renda familiar. Aqui é possível observar, no sentido dado por Zelizer (1996), uma inversão de significados: os animais, antes em sua maioria úteis à segurança das casas, são a partir das últimas décadas predominantemente membros da família e uma fonte de gastos. O mercado de rações ao mesmo tempo em que se concentrou a partir das reformas liberalizantes da década de 1990 igualmente se adaptou às mudanças de significado no mercado de animais de estimação. Novas relações são forjadas durante a apresentação de novos 
itens de mercados os quais supõem maior cuidado com os animais, como as rações premium.

O relato da trajetória dos negócios da família Sens e sua passagem do setor agropecuário dedicado a animais de grande porte e que se especializa com exclusividade no setor de animais de estimação mostra não só este processo de mudança como também a diversidade das relações de interinfluência entre a colocação de novos itens de mercado à disposição dos clientes ao mesmo tempo em que a busca de novos itens especializa determinados setores numa dupla entrada.

\section{Referências}

A FORÇA dos nutrientes. Petbr. 2003 <www.petbrasil.com.br> (1ํo jul. 2013).

ABINPET. Valor do mercado pet na América Latina sobe $40 \%$ entre 2010 e 2015. $2016<$ http://abinpet.org.br/site/> (5 maio 2016).

ANFALPET [Associação Nacional Fabricantes de Alimentação para Animais de Estimação]. Perfil pet food 2015. São Paulo, 2015 <www.petrede.com.br/tag/ anfalpet/> (10 jun. 2016).

AS PERSPECTIVAS do mercado pet brasileiro. Revista Negócios Pet. $2011<$ www. rnpet.com.br/materias-as-perspectivas-do-mercado-pet-brasileiro> (10 out. 2012).

BARNES, N. G. A market analisys of the US pet food industry to determine new opportunities for the cranberry industry. Center for bussiness research, University of Massachussetts, Dartmouth, 2005.

BOURDIEU, Pierre. A distinção: crítica social do julgamento. São Paulo: Edusp, 2008 .

BOURDIEU, Pierre. O campo econômico. Política \& Sociedade, v. 4, n. 6, p. 15-58, 2005.

BOURDIEU, Pierre. As estruturas sociais da economia. Lisboa: Instituto Piaget, 2000.

BOURDIEU, Pierre. Ce que parler veut dire: l'économi e des échanges lingüistiques. Paris: Fayard, 1982.

BOURDIEU, Pierre. Razões práticas: sobre a teoria da ação. Campinas: Papirus, 1996.

BOURDIEU, Pierre. Le couturier et sa grife: contribuition à une theorie de la magie. Actes de la Recherche em Sciences Sociales, v. 1, n. 1, p. 7-36, 1976.

BRASIL. Ministério da Agricultura, Pecuária e Abastecimento. Instrução Normativa ${ }^{\circ}$ 9, de 09 de julho de 2003. Regulamento técnico sobre fixação de padrões de identidade e qualidade de alimentos completos e de alimentos especiais destinados a cães e gatos. Diário Oficial, Brasília, 14 de julho de 2003.

BRASIL. Ministério da Agricultura, Pecuária e Abastecimento. Decreto no 6296, de 11 de dezembro de 2007. Inspeção e fiscalização obrigatórias dos produtos destinados à alimentação animal. Diário Oficial, Brasília, 12 de dezembro de 2007. 
BRASIL. Ministério da Agricultura, Pecuária e Abastecimento. Instrução Normativa $\mathrm{n}$ o 30, de 5 de agosto de 2009. Estabelece critérios e procedimentos para o registro de produtos, para rotulagem e propaganda e para isenção da obrigatoriedade de registro de produtos destinados à alimentação de animais de companhia. Diário Oficial, Brasília, 7 de agosto de 2009.

DIGARD, Jean-Pierre. Le tournant obscurantiste em Anthropologie: de la zoomanie à l'animalisme occidentaux. L'Homme, v. 203-204, n. 3, p. 555-578, 2012.

DIGARD, Jean-Pierre. Les animaux révélateurs des tensions politiques em République Islamique d'Iran. Etudes Rurales, v. 165-166, n. 1, p. 123-131, 2003 [Editions de L'EHESS, 2004].

DIGARD, Jean-Pierre. La construction social d'un animal domestique: le pitbull. Anthropozoológica, v. 39, n. 1, p. 17-26, 2003.

DOUGLAS, Mary; ISHERWOOD, Baron. O mundo dos bens: para uma antropologia do consumo. Rio de Janeiro: Editora da UFRJ, (2006[1979]).

FLIGSTEIN, Neil. Social skill and the theory of fields. Sociological Theory, v. 19, n. 2, p. $105-125,2002$.

FLIGSTEIN, Neil. Le mythe du marché, Actes de la Recherche, v. 139, n. 3, p. 12, 2001.

FLIGSTEIN, Neil. Mercado como política: uma abordagem político-cultural das instituições de mercado. Contemporaneidade e Educação, v. 6, n. 9, p. 26 -55, 2001a.

FLIGSTIEN, Neil. The transformation of corporate control. Cambridge: Harvard University Press, 1990.

FRANKLIN, Adrian. Animals \& modern cultures - a sociology of human-animal relations in modernity. London: Sage, 1999.

FREEDMAN, Adrian H. et al. Genome sequencing highlights the dynamic early history of dogs. PLoS Genet, v. 10, n. 1, $2014<10.1371$ /journal.pgen.1004016>.

GATES, Margaret. A brief history of commercial pet food. Feline Nutrition, [S. i.], $2008<$ http://feline-nutrition.org/features/a-brief-history-of-commercial-pet-food> (17 fev. 2017).

GROMPER, Matthew E. One billion dogs? What does that means? $2014<\mathrm{http} / / / \mathrm{blog}$. oup.com/2014/03/one-billion-dogs-wildlife-conservation> (10 jul. 2016).

INGOLD, Timothy. Da transmissão de representações à educação da atenção. Educação (Porto Alegre), v. 33, n. 1, p. 6-25, 2010.

INGOLD, Timothy. Humanidade e animalidade. RBCS, v. 28, $1995<$ www.anpocs.org. br/portal/publicacoes/rbcs_00_28/rbcs28_05.htm>.

KOERNER, Brendan I. That pudgy pooch is an industry's best friend. New York Times, 30, novembro, $2003<\mathrm{http}$ :/query.nytimes.com/gst/fullpage.html?res=9B06E4D8123 AF933A05752C1A9659C8B63\&pagewanted=all $>$ (1ํㅡㄹ. 2017).

KULICK, D. Animais gordos e a dissolução de fronteiras entre as espécies. Mana: Estudos de Antropologia Social, v. 15, n. 2, p. 481-508, $2009<10.1590 / \mathrm{S} 0104-$ 93132009000200006>. 
LARSON, Greger et al. Rethinking dog domestication by integrating genetics, archeology, and biogeography. Proceedings of the National Academy of Science USA, v. 109 , n. 23 , p. 8878-8883, 2012 <www.pnas.org/content/109/23/8878> (12 maio 2016).

MARICHALAR, Xabier G. El mercado de la alimentación y accesorios para mascotas en Brasil. São Paulo: Icex [Instituto Español de Comercio Exterior], 2006.

MARS compra parte de negócio de alimento para animais da P\&G. 2014. Revista Exame, 9 abr. $2014<$ http://exame.abril.com.br/negocios/noticias/mars-compra-partede-negocio-de-alimento-para-animais-da-p-g> (17 ago. 2016).

MAZON, Marcia S. Padrões de qualidade e segurança alimentar no terreno institucional brasileiro. Dados, v. 52, n. 4, p. 1003-1044, $2009<10.1590 /$ S001152582009000400006>.

MORELL, V. Evolução: do lobo ao cão. SCIAM, ano 13, n. 159, p. 26-34, 2015.

MOURA, W. G. A construção social do mercado pet food no Brasil: estudo de caso da família Sens. 2013. Trabalho de Conclusão de Curso (Graduação em Ciências Sociais) Departamento de Sociologia, Centro de Filosofia e Ciências Humanas, Universidade Federal de Santa Catarina, Florianópolis, 2013.

MUNDO das marcas. Purina. 2006a <http://mundodasmarcas.blogspot.com. br/2006/05/purina-advancing-life.html $>$ (25 set. 2015).

MUNDO das marcas. Mars. 2006b < http://mundodasmarcas.blogspot.com.br/2006/06/ mars-every-day-new-idea.html $>$ (29 set. 2015).

PERROTTA, Ana P. Abate bovino e rede industrial: um estudo sobre a introdução e gestão racional e econômica das emoções dos animais. Política e Sociedade, v. 15, n. 33, p. 68-96, $2016<10.5007 / 2175-7984.2016$ v15n33p68>.

RITTO, C.; ALVARENGA, B. A casa agora é dos cães - e não das crianças. Veja, 4 jun. $2015<\mathrm{http}$ //veja.abril.com.br/noticia/entretenimento/a-casa-agora-e-dos-caes-enao-das-criancas $>$ (12 jan. 2016).

SEGATA, Jean. Le cosmopolitique de la dépression: biosocialité dans une ethographie multi-espéces. Vibrant, v. 12, n. 1, p. 290-320, $2015<10.1590 / 1809-43412015$ v12n $1 \mathrm{p} 290>$.

SEGATA, Jean. Os cães com depressão e seus humanos de estimação. Anuário Antropológico 2011/II, Brasília: UnB, 2012. p. 177-204.

TAVARES DE ALMEIDA, Maria Hermínia. Negociando a reforma: a privatização de empresas públicas no Brasil. Dados, v. 42, n. 3, p. 421-451, $1999<10.1590 /$ S001152581999000300002>.

THOMAS, Keith. O homem e o mundo natural: mudanças de atitude em relação às plantas e aos animais (1500-1800). São Paulo: Companhia das Letras, 2010 [1983]).

ZELIZER, Viviana. Economic lives: how culture shapes the economy. Princeton University Press, 2011.

ZELIZER, Viviana. A negociação da intimidade. Petropolis: Vozes, 2011a. 
ZELIZER, Viviana. Human values and the market: the case of life insurance and death in 19th-century America. American Journal of Sociology, v. 84, n. 3, p. 591-610, 1992 [1978].

ZELIZER, Viviana. Multiple markets, multiple cultures. In: Neil Smelser J.; Jeffrey C. Alexander (eds.). Diversity and its discontents. Princeton: Princeton University Press, 1999. p. $193-212$.

ZELIZER, Viviana. Princing de priceless child: the changing social value of children. Princeton: Princeton University Press, 1994 [1985].

ZUINI, P. Mercado pet supera crise com inovação. Revista PEGN, 29 out. 2015 $<$ http://revistapegn.globo.com/Banco-de-ideias/noticia/2015/10/mercado-pet-superacrise-com-inovacao.html> (17 ago. 2016).

Recebido em: 18 jun. 2016

Aprovado em: 17 fev. 2017

Autora correspondente:

Marcia da Silva Mazon

Travessa da Liberdade, 457 - casa 118

Condomínio Recanto da Liberdade - Campeche

88063-210 Florianópolis, SC, Brasil 